27. Khilov V.S., Triputen, V.M. Effect of The Types of Drive Systems of DRGs on The Rock Breaking Dynamics. 158-169. Seventh International Conference IEEE 2020 on Energy Efficient Systems (ESS) 2020.

28. Glukhova N.V., Khilov V.S. 2020. Integrated Assessment of the State of Sewage Mine Waters Based on Gas-Discharge Radiation Method. 129-144. XIV International Scientific and Practical Conference "Ukrainian School of Mining" as a step towards a new direction of innovative technologies and intelligent systems in the mining industry, v.132

https://doi.org/10.31713/m1115

\title{
IMPROVING THE EFFICIENCY OF THE TECHNOLOGICAL COMPLEX FOR THE DEVELOPMENT OF MARINE GAS AND GAS HYDRATE DEPOSITS
}

\author{
Pedchenko N.M. \\ National University «Yuri Kondratyuk Poltava Polytechnic», \\ $\mathrm{PhD}$ Student, Ukraine
}

\begin{abstract}
Purpose. Substantiation and the development of principled schemas, acceptable to the existing technique, methods of production and transportation of natural gas of the offshore fields of gas or gas hydrates. Improving their efficiency by way maximum reduction of the energy consumed is the result of complex consideration of thermal properties and parameters of interaction of the components system within the deposit what is developing.

Findings. The technology of gas hydrates withdrawing with the productive reservoir without energy consumption for the phase transition is proposed. The question of enrichment directly in situ of rocks what containing gas hydrates is considered. Dissociation of residue of the gas hydrates in the rock must be implemented at the expense low potential energy of sea water. The expediency of a compatible development of gas hydrate and gas fields, by way binding of free gas in gas hydrates at the expense of presence of necessary temperature and pressure conditions at passes it through the thickness of sea, is proved. Expediency combination into one a chain of the proposed technology of the development of the offshore fields of gas and gas hydrate with technology of gas transportation in hydrate form and its storage in terrestrial storages is proved.

Originality. Ability to extract gas hydrates from the productive reservoir without the energy consumption for the dissociation, by creating conditions of its recrystallization as a result compatible actions of flooded streams of sea water in a mixture with an abrasive material and pressure fluctuations, is proved. Ability to extract natural gas from residue of gas hydrates in the pulp at the expense of low energy of seawater and changes of its pressure with depth is proved.
\end{abstract}


Practical implications. The proposed gas hydrate technology creates important preconditions for the development of small and medium remote gas deposits (including the gas hydrate), the network of terrestrial storages of the hydrates, improves the efficiency and competitiveness of technology marine transport of natural gas in the hydrate form. Key elements of the technological complex production, transportation and storage of gas offshore fields of the gas and gas hydrate on the basis of gas hydrate technology are proposed and proved.

\section{Introduction}

Level of consumption of natural gas is growing. Its easily accessible reserves are depleted rapidly. However, about $80 \%$ of the gas fields, which open in the world, is a relatively small or remote from the transport infrastructure. Most of them are located on the shelf of seas (in the form of traditional deposits and in hydrate form). Thus, the existing technologies of the development do not contribute to the rational use of a substantial part of their resources (example, construction of pipelines can be economically unjustified).

Water molecules and low molecular components of natural gas have the property under certain conditions of temperature and pressure to form relatively stable compounds - gas hydrates. This property caused to the fact that in the depths of the earth and the waters of the World's ocean emerged almost unlimited resources of natural gas in solid hydrate form, which available most countries. Gas hydrates are crystalline compounds (clathrates) of the structure of the general formula $\mathrm{MnH}_{2} \mathrm{O}$, where $M$ - a molecule of gas hydrate-forming; $n-$ the number that describes the composition and depends on the formation of gas hydrates $(n=6-17)$. One volume of water contains the 70-210 volumes of gas.

Potential worldwide resources of the gas hydrate are estimated at $2.1 \cdot 10^{16} \mathrm{~m}^{3}$ (Kvenvolden, 1993). They approximately $98 \%$ are concentrated in the World Ocean at depths of 200-700 meters, and in the bottom sediments with thickness of 400-800 m. (Hence, their development does not require drilling of the ultra-deep wells).

In the Black Sea area gas resources in the hydration state is estimated at $25 \cdot 10^{12}-70 \cdot 10^{12} \mathrm{~m}^{3}$ (in the economic zone of Ukraine $7 \cdot 10^{12}-20 \cdot 10^{12} \mathrm{~m}^{3}$ ) (Vasilev \& Dimitrov, 2002).

Natural gas hydrates more evenly are distributed on the planet than a source of oil and gas. The wide introduction of technology their development can lead to inexpediency of imports of natural gas 
from other countries. Thus, natural gas hydrates will play an important role in the global energy balance as one of the major unconventional resources in the near future.

Analysis of the data concerning the today's known gas hydrates kicks and their features in the oceans and lakes permits to conclude that the submarine gas hydrates can form clusters, which are located at great sub-bottom depths (hundreds of meters) and are controlled by the zones of percolation in the conditions of distributed fluids filtering, or are located in the close proximity to the sea floor, at the bottom or at very shallow sub-bottom depths (first meters).

Most of hydrates are present in coarse-grained sedimentary deposits, but when performing the research, hydrates were also found in fine-grained sediments as small inter-layers, lenses and thin, almost vertical loads. For example, the study of well NGHP-01-10 detected a powerful range of fractured clays, the hydrates content of which is among the highest in the world (Timothy, 2010).

Formed in reservoir conditions hydrated crystals can be dispersed in the pore space without destroying of pores and with their destruction, may be in the form of particle $5-12 \mathrm{~cm}$, in the form of lenses of small size and in a well-seasoned, of long clean hydrate layers the thickness to a few meters.

There are three basic methods of extracting gas from gas hydratebearing layers: lowering the pressure below the hydrate formation equilibrium at a designed temperature, heating hydrate-containing rocks to temperatures higher than the equilibrium and their mechanical disintegration. Also solutions are known, suggesting to use the reagents, which can influence the chemical activity of water and gas, causing a shift in the equilibrium of formation and dissociation reactions of gas hydrates to the lower temperatures zone (the so called inhibitors: methanol, ethylene glycol, electrolyte solutions, etc.). Most of the presently known methods for gas hydrate deposits development suggest a combination of the above methods.

Classic examples of thermal methods for gas hydrate deposits development is the US Patent 6192691: it suggests hot water injection under the gas collecting dome, installed over the bottom set gas hydrates accumulation, and application US 20050161217: it suggests electric heating of a productive reservoir and to extract the gas re- 
leased through the production well. The international application WO 2007/136485 suggests gas hydrate reservoir heating by means of the laser radiation energy. An example of the combined action on a gas hydrate reservoir (in this case thermal energy and inhibitors are meant) are patents US 4.424.866 and US 6.733.573.

However, the disadvantage of thermal methods for gas hydrate deposits development is significant energy consumption. Thus, besides the relatively small energy consumption for gas hydrates dissociation (about 7\% of the extracted gas combustion energy), most of them will be used to heat hydrate saturated stratum's rocks and its surface and roof rocks. Moreover, considering the thermal and physical properties of rocks and gas hydrates, it is obvious that the heat action zone in the reservoir will be limited to a few meters.

The most profit-proved technology of gas hydrate deposits development in terms of energy costs is reducing the reservoir pressure below the equilibrium, followed by free gas extraction. An example the above method is described in international application WO 2007/072172, which suggests reducing pressure in the gas hydrate reservoir by degassing the lower horizons.

However, this method is available for deposits, where hydrates saturation is insufficient and a reservoir has sufficient gas or water permeability. Naturally, hydrate saturation growth (and, hence, permeability reducing), the above method's efficiency plunges.

Another disadvantage of the said method, based on reducing pressure in the hydrate bearing reservoir, is associated with the secondary anthropogenic formation of hydrates in the bottom-hole formation zone due to the Joule - Thomson effect and manifestation of effect self-preservation of hydrate in a layer. For example, the initial temperature of the reservoir $283 \mathrm{~K}$ and $5.74 \mathrm{MPa}$ pressure coefficient Joule - Thomson is 3-4 $\mathrm{K}$ at $1 \mathrm{MPa}$ depression. Thus, at the depression of 3-4 MPa, the bottom-hole temperature may reach the freezing point of water. The process is additionally complicated by the fact that the rocks containing over $60 \%$ of hydrate is virtually gas impermeable (Basniev, Kul'chitskiy, Shchebetov \& Nifantov, \& Nifantov, 2006). As a result, gas hydrate (hydrate layer) for a long time, which will depend on the speed of heat supply and will be determined by its thermo-physical properties and around in the sole and roof of rocks, will be "reliably", preserved by the ice layer. 
In addition, the results of experimental studies gas filtration through hydrate-saturated the rocks that are given in (Beznosikov \& Maslov, 1975), indicate that the permeability of gas into two, three or more orders less than the permeability of unsaturated by hydrates samples. Low permeability is associated and with initial water saturation because for some its meanings gas hydrate forms in all volume of the porous medium, filling all pores and micro-cracks.

In addition, gas hydrates could serve as "cement", for particles of the formation's rock. Dissociation of clathrates in sediments causes abnormally high porosity and releases large masses of water (Kvenvolden, 1993). Thus, the destabilization of gas hydrates will lead to a significant weakening of sedimentary structures in the dissociation zone. Therefore, destruction of a gas hydrate structure by reducing the pressure, raising temperature or introducing inhibitors may lead to decompaction of the hydrate cemented rock and transforming them into an over wetted unstable structure with gas bubbles inclusions. Due to the depression, created for extracting gas, over wetted stratum destruction and suction of an unlimited number of rock species together with water and gas into the reservoir's bottom hole, will inevitably happen, making for further exploitation of the well practically impossible.

There are also ways to simultaneously reduce pressure and heat supply to wells. Moreover, hydrate dissociation in the reservoir is mainly due to lower pressure; and heat, supplied to the bottom-hole, permits reducing the zone of secondary hydrate formation, thus positively affecting the gas flow rate. However, a combination of these methods does not solve the above disadvantages.

Methods are presented in applications US 2008/0088171, WO 00/47832 and RU 2004106857/03 suggests open-cut mine development of marine gas hydrate deposits by their mechanical disintegration. Thus, the method of selection of bottom hydratecontaining sediments by underwater excavators, their lifting to the surface in containers and accumulation of received gas under the dome, located in the ship's bottom, is described in the application US 2008/0088171.

The method of extracting gas hydrates from the seabed, described in the application RU 2004106857/03, suggests using an extraction device in the form of a self-propelled harvester and a device, 
delivering them to the surface as barge, which emerge to the surface own.

The method of extraction bottom and sub-bottom hydrates described in the application WO 00/47832, provides destruction of gas hydrate layer by compressed air and special high-density solution (or water pressured), served through the pipe, separation from the bottom of the pieces hydrate, them collection and dissociation. The possibility of heating the compressed air and fluid is also stipulated. However, the surface of gas discharge areas, which are located near the bottom gas hydrates deposits, is mainly covered with a layer of sediments (often submarine hydrates occur, starting from a depth of 0.4 to $2.2 \mathrm{~m}$ below the bottom surface (Shnyukov, Gozhik, Krayushkin \& Klochko, 2007) and based on the speed of attenuation of stream energy in the aquatic environment an insignificant depth of them cutting the effectiveness of this method will be questionable.

This also applies to the case, characteristic for most deposits of gas hydrates - attitude of volume of gas hydrates up the mineral party is insignificant (hydrates fills the pores or cements mineral party of layer). So, using a method, suggesting the gas hydrates disintegration by means of air or liquid streams, and also using the quarry rock cutting machinery, located directly on the seabed, will be inefficient.

\section{The main part of the article}

\subsection{Analysis of technology of the borehole hydro- mining}

In mining industry, the method of minerals hydro-mining (Arens et al., 2007) is well know, it stipulates drilling the well in the deposit field, reducing the density of rocks in the place of its location by means of transferring it into a moving state by means of a hydraulic monitor jet and extracting the hydraulic fluid (pulp) to the surface. Analysis of technological operations of the borehole hydraulic mining (bearing of the productive strata, hydraulic-ablation, the formation of a pulp, transportation from the unit to the inductive apparatus, raise of the hydraulic-mixture to the surface, enrichment) and consistency of their implementation has shown perspective of implementation of this method to develop of the gas hydrate deposits.

Hydraulic method to separate rocks from the block carries out 
through water jets which flow from jet-apparatus, main task which is the formation and direction of these jets. The hydraulic-production aggregate, which represents a combination of borehole jet and hoisting and transport mechanism of the borehole for extracting of the pulp to the surface, is mounted in a borehole. The transformation of static water pressure in the kinetic energy of the jet occurs in jet. The rate of the water increases as a result of decrease of cross section of the nozzles at a constant it expenditure (the potential energy of water nozzle converted into kinetic, stock of which with distance from nozzles is lost). In this case in the technologies borehole hydraulic-production jet is a working organ for destruction and transportation of rocks.

The mechanism of the process of the primary hydraulic destruction is characterized by versatility action of water on the block, which includes destruction due to shear stresses, impact, filtration pressure (Rehbinder, 1980), and at every point is described by the following formula

$$
\tau \geq\left(c_{t}-c_{p}\right)+\left(\gamma H \cdot 10^{-2} \operatorname{tg} \varphi_{t}-K_{l} \gamma H \cdot 10^{-2} \lg \varphi_{p}\right),
$$

where

$\tau$ - destructively-shear stresses, $\mathrm{MPa}$;

$c_{t}$ - temporary adhesion (maximum), $\mathrm{MPa}$;

$c_{p}$ - prolonged adhesion, $\mathrm{MPa}$;

$\varphi_{t}$ - temporary angle of internal friction, ${ }^{0} \mathrm{C}$;

$\varphi_{p}$ - prolonged angle of internal friction, ${ }^{0} \mathrm{C}$;

$\gamma$ - density of rocks, $\mathrm{kg} / \mathrm{m}^{3}$;

$H$ - depth of development, m;

$K_{l}$ - coefficient of lateral pressure.

Thus penetrating into a block at the expense of filtration through pores and cracks water lowers the strength of rocks (Rehbinder, 1980), causes local hydraulic fracturing and destruction. This should taken into consideration by adjusting laid dependence at the studying the mechanism of grinding of a particular block and introduction of appropriate coefficients. But in the process of movement of the jets in multiphase systems (water, solid inclusions, gas) phenomena occur so complex that sufficiently reliable methods of analytical determination does not exist today.

\subsection{The method of development of gas hydrate deposits}


Considering disadvantages of technology introduced above, method development of marine gas hydrate of deposits (Fig. 1) is proposed, which provides:

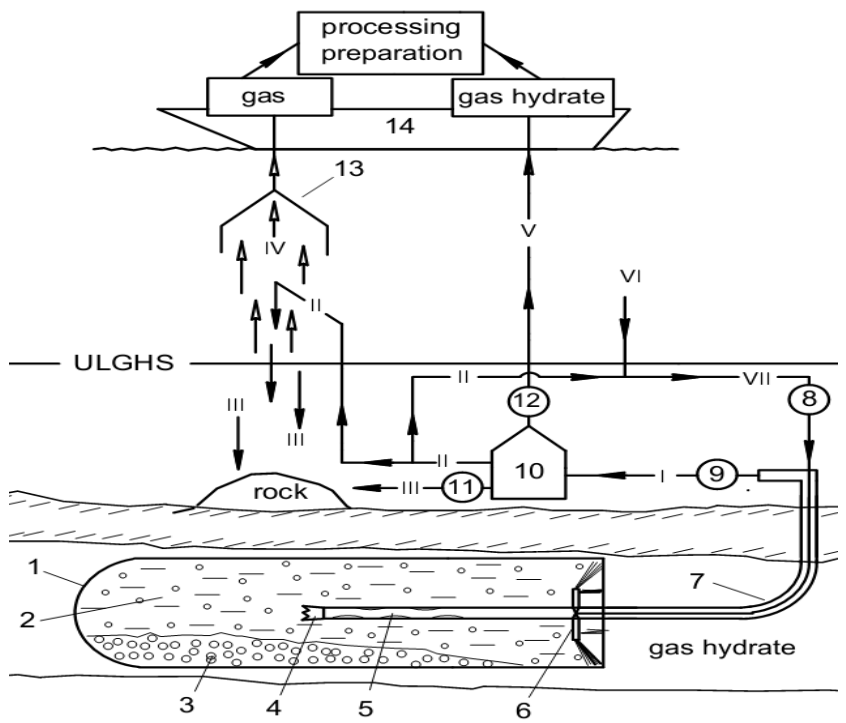

Fig. 1. Principal diagram of the method for marine gas hydrate deposits development: ULGHS - the upper limit of gas hydrate stability; 1 - excavation in the hydrate-saturated reservoir; 2 - space in the excavation site filled water-hydrate mineral pulp; 3 - sediment of rock solid inclusions; 4 - drill bit; 5 - pulp intake; 6 - jet gun device; 7 -well; $8,9,11,12$ - pump; 10 - gravity separator; 13 - gas collecting dome; 14 - production platforms; streams; I - water-hydrate mineral pulp; II - gas hydrates depleted pulp; III - empty rock; IV - gas released from the pulp as a result of gas hydrate dissociation; V - water gas hydrate mixture; VI - sea water;

VII - working fluid for rock disintegration (sea water and pulp mixture)

- disclosure of hydrate layer by horizontal boreholes, of the powerful - of vertical or obliquely directed to the their sole (7);

- the impact on the productive layer (starting with the well drilling) with the purpose of its disintegration by means of mechanical grinding at the minimum level of dissociation and gas hydrates recrystallization (due to the formation of local zones for a short time under the non-equilibrium conditions) as a result of immersed jets of high-pressure mixture of water and abrasive material (stream VII) using hydro-monitor (6). Notably, to increase the output volume, 
steel stems with jet gun nozzles are extended in the operating position, occupying the position perpendicular to the well's axis (7) and, turning around it, are moving along to the contact with the front of disintegration;

- formation, as a result of mixing the grinded hydrate containing rock with water of the water-hydrate mineral pulp (2);

- gravity separation of part of the relevant density and fractional composition rock mineral inclusions (3) from the water-hydrate mineral pulp (2) at some distance behind the active operating zone;

- withdrawal of the pre-enriched water-hydrate mineral pulp from the excavation site (1) through the pulp intake (5), located behind the active operating zone, to the separator (10), located at the seabed level;

- separation from the water-hydrate mineral pulp (stream I) (under the pressure higher than that of the hydrate formation equilibrium) in a gravity separator (10) as a deposit of empty rock's part, which is pumped out with the pump (II) to the bottom or through another well - to the discharged rock (stream III) and as a fraction that comes to the surface: a mixture of water and free gas hydrates (stream V) (natural and partly recrystallized);

- supply of the separated gas hydrates in a mixture with water (flow $\mathbf{V}$ ) as of the upper flow of the separator (10) by pump (12) to the extractive a platform (14);

- selection of the gas hydrates depleted water-hydrate mineral pulp's part (stream II) after separation, adding thereto sea water (stream VI) and supply (pump 8) resulting mixture (stream VII) under pressure to hydraulic jet gun (6) for rock disintegration (solid fraction of formed mixture acts as an abrasive);

- pumping out the rest of the depleted pulp (stream II) under the gas collecting dome (13) into the sea through a pipe, the open end of which is located above the upper limit of the gas hydrate stability (ULGHS). Meanwhile, as a result of being exposed to nonequilibrium conditions and the heat exchange with sea water, dissociation of the remaining gas hydrates into gas and water is taking place in the depleted pulp;

- sedimentation of the rocks onto the bottom (stream III), accumulation of gas in the gas collecting dome (13) and its supply to the platform (14). 
The suggested method for the hydrate deposit development suggests 4 basic stages: 1) hydrate containing rock disintegration in order to transfer it into the movable state; 2) concentrating pulp in the well as result of the rock cuttings sedimentation at a certain distance behind the active layer disintegration area; 3) separation (enrichment) of free gas hydrates in the gravitational separator and reducing the volume of pulp per the volume of water gas hydrate mixture and sedimentary rocks; 4) gas release as a result of the gas hydrate residues dissociation in the process of rock passing through the thickness of sea water at the interval exceeding the upper limit of this composition gas hydrate stability.

In this method of influence the gas hydrate layer is exposed:

- of salt sea water;

- of the heat energy released at transformation of mechanical energy of the jet;

- of pulsations of pressure of the working mixture in the process of the jet work.

Thus gas hydrate for some time enters non-equilibrium conditions and partially dissociates. However, considering the heat balance of the process and features of kinetics, the impact will be short and will carry local character (in a contact zone of the working stream with the rock). As a result, dissociation of the certain part of gas hydrates is associated with rocks, will occur in one and free gas will forms hydrate in another place. In addition, the permanent presence of free gas will be the result of recrystallization of gas hydrates in zone of the destruction of rocks. The presence of compressible gaseous phase in the zone of pressure fluctuations also will be an additional factor of the impact on the layer.

Thus, the advantage of the proposed method of development of the gas hydrate deposit is as follows: 1) basic quantity of gas hydrates are extracted without the spending of energy on the a phase transition; 2) dissociation of the gas hydrates residue in the pulp for the extraction of gas is carried out due of low potential energy of sea water and changing of it pressure with depth.

\subsection{Transportation of produced products}

Regardless of the form of gas in the deposit (free gas or gas hydrates), the level of perfection of technical and technological solu- 
tions of operations of its preparation and transportation significantly influences on the efficiency of the technology of extraction of gas too. Nowadays natural gas is transported by sea pipelines in the gaseous state and by tankers in liquefied state (LNG-technology). However, in recent years, technology based on the ability of gas molecules and water form gas hydrates, is actively developed. In the composition of gas hydrate considerable volumes of gas can long be stored at atmospheric pressure and a slight negative temperature. This technology has undeniable prospects for implementation in the near future, but needs improvement and testing of its elements.

At present several concepts the transportation of gas in hydrate form are considered. The technology for the transportation of nonequilibrium conditions (small negative temperature and atmospheric pressure) is the most attractive. It needs the production of gas hydrates in the most stable form under these conditions. At present granules of the gas hydrate is proposed transport today (Gudmundsson, 1996). However, over time freezing granular hydrates complicates unloading (Dawe, Thomas \& Kromah, 2003). Also granular gas hydrate only by $78 \%$ fills volume of vehicles or storages (Gudmundsson, Graff \& Kvaerner 2003). Besides, much of the total surface area of the granules and system of open channels between channels granules stimulates the process of volumetric dissociation of the gas hydrate mass. Keeping them stable at atmospheric pressure needs additional costs for cooling to temperatures below a $258 \mathrm{~K}$. Monolithic blocks of large size are a good option.

However, today the industrial technology of production does not exist (Yakushev, Gerasimov, Kwon, \& Istomin, 2008). Due to thermal properties and features process of transportation and storage, gas hydrates is proposed to produce in the form of gas hydrate of blocks maximum cooled large, preserved with the layer of ice and refrigerated in the production process to the desired level (Pedchenko, Pedchenko, 2012).

This technology provides intensive production synthetic gas hydrates. Moreover it must have maximum gas content (up to $160 \mathrm{~m}^{3} / \mathrm{m}^{3}$ ). According to the research the formation of hydrates proposed to perform in the contact devices on the basis of jet devices (ejectors with elongated mixing 
chamber or jet devices with free stream).Their application allows increasing efficiency and simplify the process of technological design of technology (Pedchenko, Pedchenko, 2014) (Fig. 2).

$a$

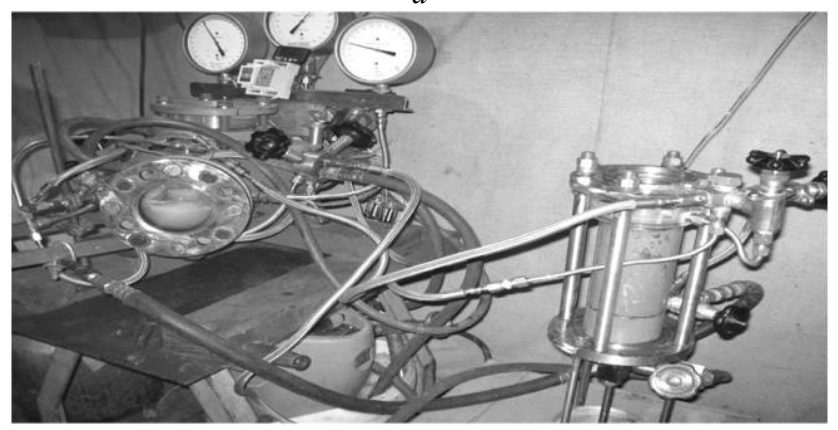

b

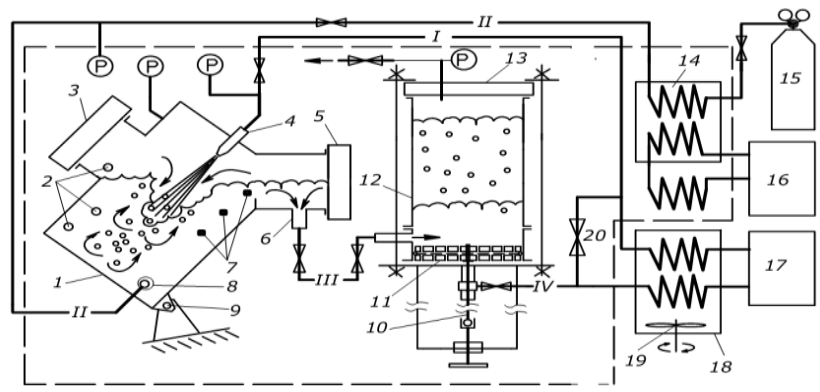

Fig. 2. The laboratory unit for continuous production of gas hydrates: a) photos; b) scheme ; 1 - reactor; 2 - temperature sensors; $3,5,13$ - observation windows; 4 inkjet apparatus; 6 - branch pipe; 7 - LEDs; 8 - bubbler; 9 - hinge; 10 - rod; 11 plunger with filter; 12 - separator; 14,18 - exchanger; 15 - balloon; 16 - refrigerator; 17 - pump; 19 - mixer; 20 - valve; flows; I, IV - water; II - gas; III - mixture of hydrate and water

Blocks will be formed from the previously cooled mixture of crushed and granulated hydrates of minimum porosity in the respective proportion. This solution allows to obtain blocks of uniform density and to waive the need them cooled (Fig. 3). 

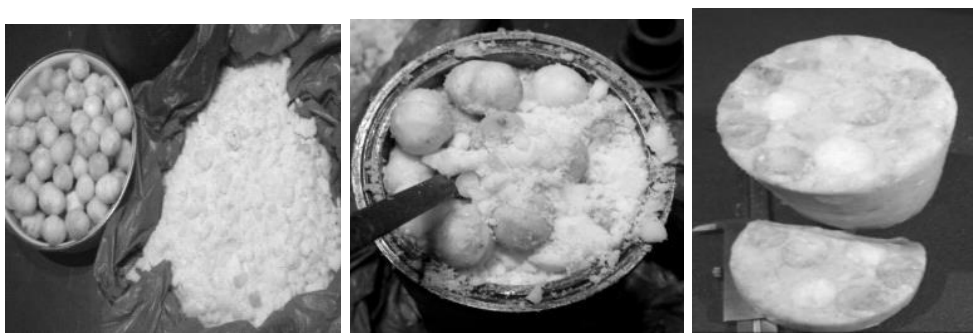

Fig. 3. Transverse section of the gas hydrate block after the formation

To increase stability and the mechanical strength of hydrate blocks necessary force to preserve with the layer of ice. For this purpose, on their surface freeze crust 1-2 mm is sufficient (ice crust, formed as result selfpreservation is thinner) (Gudmundsson \& Parlaktuna 1991).

In the study of the force preservation of the gas hydrate blocks the need re-application of water from endurance to crystallization of the previous layer was established. In the first application main part of the pores was blocked and «cementing» of the surface of the sample to a depth of water penetration. In the second - pores are blocked completely, surface defects are smoothed and ice layer are frozen (Fig. 4).

Consequently, the existence of the sample in equilibrium conditions (for example, as a result of application of water) thickness of the ice crust is determined by the balance of energy and amount of water in its pores and on the surface. Thus, forced preservation allows you to create for of gas hydrate under a layer of ice conditions its stability while the sample itself may be in equilibrium conditions.

$a$
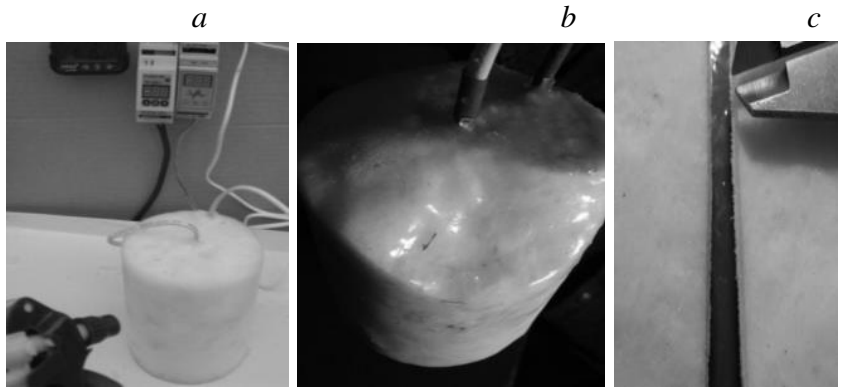

Fig. 4. Forced conservation of sample of gas hydrates with the ice layer: $a$ - application of water; $b$ - gloss of a layer of ice on a sample; $c$-ice layer on a section of a sample 
The method of production of gas hydrate in the form of blocks with internal energy source, preserved layer of ice is proposed, considering the properties of gas hydrate and experimental results (Fig. 5,6). It includes: gas hydrate production with a significant water content, its separation, enrichment of the gas hydrate mass by transferring of the residue water (between the crystalline and captured) to the hydrate and increasing filling with the gas molecules of the crystal lattice, single the cooling of gas hydrates $(T \leq 258 \mathrm{~K})$ granulating one part and crushing of the gas hydrates another, the formation of blocks with the mixtures forced their conservation with the layer of ice.

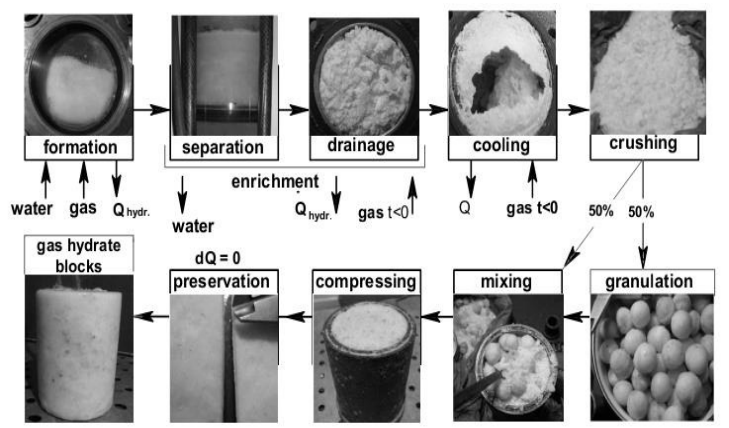

Fig. 5. Scheme of method of production of gas hydrate blocks

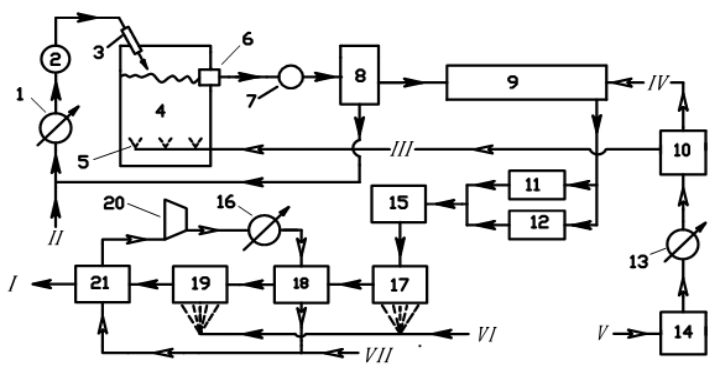

Fig. 6. Method of production of gas hydrate blocks: 1 - cooling of water; 2 - water pumping; 3 - feed water stream into the reactor; 4 - formation of gas hydrates; 5 bubbling gas; 6 - selection of gas hydrates; 7 - vibration treatment; 8 - separation; 9 - concentration and cooling; 10 - crushing of hydrate; 11 - granulated of hydrate; 12 - separation of gas; 13 - cooling of gas; 14 - preparation of gas; 15 - formation of blocks; 16 - cooling of air; 17 - the first water supply to the blocks; 19 - the second water supply on the blocks; 18 - cementing surface; 21 - freezing of layer of the ice; 20 - air circulation; stream: I - blocks; II, VI - water; III - methane; IV - condensate; V - gas; VII - air 
For realization of this method project pilot plant with a capacity of 20 thousand gas $\mathrm{m}^{3} /$ day (140 tons per day hydrate) is developed (Fig. 7). Pilot plant is designed for production of gas hydrate blocks weight to $250 \mathrm{~kg}$. Gas consumption for technological needs of the pilot plant during the summer installation is $2400 \mathrm{~m}^{3} /$ day (or $12 \%$ of its capacity). At low temperatures the gas consumption is reduced to $568 \mathrm{~m}^{3} /$ day (or $2.8 \%$ ).

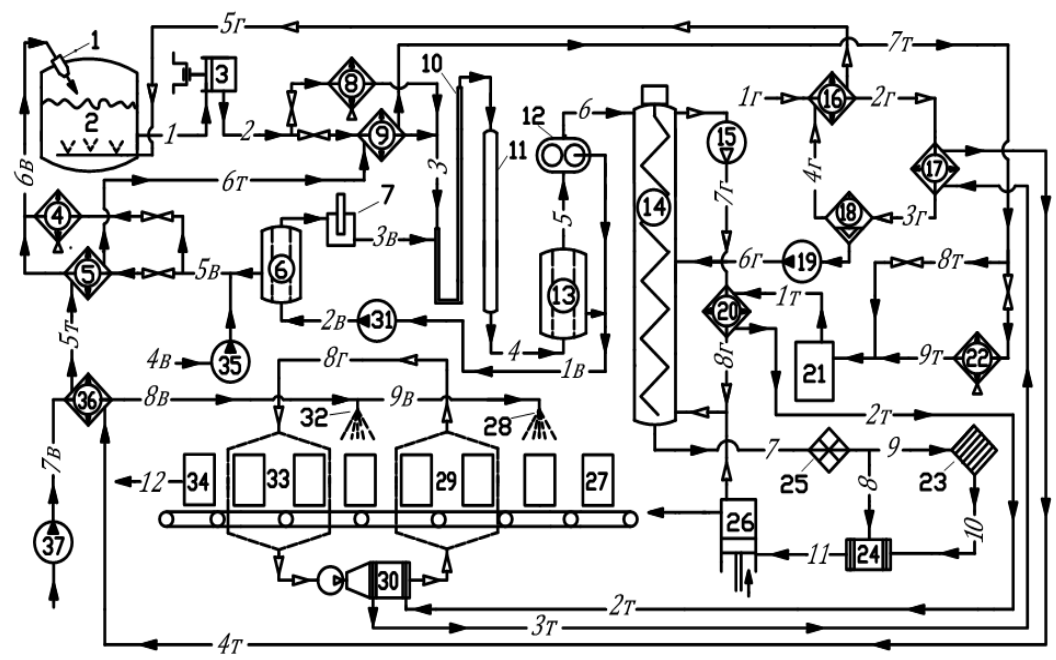

Fig. 7. Principle scheme of the installation for the production of hydrocarbon gas hydrate in the form of blocks capacity of $140 \mathrm{t} /$ day (20 thous. $\mathrm{m}^{3} /$ day of gas) 1 - inkjet apparatus; 2 - reactor; 3,7,19,31,35,37 - pump; 4,8,22,30 - device of air cooling; 5,9,16,17,20 - heat exchanger; $6,13.18$ - separator; 10 - coiled pipe;

11 - moderator; 12 - squeezing device; 14 - column of draining of gas hydrates; 15 - compressor; 21 - refrigerator; 23 - granulator; 24 - mixer; 25 - straw chopper;26 - press for the formation of gas hydrate blocks; 27,34 - gas hydrate blocks; 28,32 nozzle; 29,33 - zone of blowing gas hydrate blocks; streams: 1-4 - mixture of gas

hydrate and water; 5,6 - crude gas hydrate mass; 7 - drained and cooled gas hydrates; 8,9-crushed hydrates; 10 - granular hydrates; 11 - mixture of crushed and granulated of gas hydrates; 12 - gas hydrate blocks; $1_{\Gamma}-3_{\Gamma}-$ raw gas; $4_{\Gamma}, 5_{\Gamma}-$ dry gas; $6_{\Gamma}-$ condensate $; 7_{\Gamma}, 8_{\Gamma}-$ gas draining of; $1_{\mathrm{B}}-9_{\mathrm{B}}-$ water, $1_{\mathrm{T}}-9_{\mathrm{T}}-$ carrier of cold

Thus the gas hydrate blocks manufactured in accordance with the proposed technology (Pedchenko, Pedchenko, 2012) can be regarded as «devices» for concentrate the gas with an internal energy source. 
They suitable for long-term storage and transportation at atmospheric pressure and a slight negative temperature.

Deleting from the main part of deposit of the products in the form of gas hydrate in conjunction with the technology transport and storage of gas in hydrate form will significantly reduce the specific consumption and increase the competitiveness of the project.

\subsection{The method of development}

Today the natural gas transports by the pipelines and LNGtankers. However such transport technology, based on the significant investments, will be effective at presence of significant confirmed gas resources on this field (Seungyong, 2001). In many cases the traditional technologies of transport of gas can not fully solve the demands of projects of development of marine fields.

In the article (Gudmundsson \& Borrehaug, 1996) showed, that capital costs on a technological chain of the NGH- technologies for transporting 4 billion $\mathrm{m}^{3}$ of natural gas at a distance 5.5 thousand. $\mathrm{km}$ were lower on the $26 \%$ compared to the LNG-technology. Application of NGH-technologies will be economically feasible, starting from a distance of $1000 \mathrm{~km}$, for while LNG-technologies this distance should be greater than $3000 \mathrm{~km}$ (Gudmundsson, Graff \& Kvaerner, 2003).

Gas hydrates have the property at relatively low pressures to concentrate large volumes of gas (up to 160 volumes natural gas in one volume hydrate). But this figure is almost is four times smaller compared to liquefied natural gas. Considering the density of the hydrate, the specific contents of natural gas and rather soft thermo-baric conditions of storage, $\mathrm{NGH}$-tankers can be are built at least twice as big as LNG-analogues and can transport 250 thousand. $\mathrm{m}^{3}$ of cargo (Gudmundsson \& Borrehaug, 1996). The equipment of the factories for the formation of gas hydrates do not needs special of a unique equipments in contrast to the factories the liquefaction of natural gas greatly reduces the cost of NGH-technology (Kanda, 2006). In addition, the power of lines for the production of the gas hydrate may be in 4 times lower than in line production of LNG, without increase of its cost. This gives an opportunity smoothly adjust the production when changing the demand for natural gas (Gudmundsson, Parlactuna \& Khokhar, 1994) 
Proceeding from listed above considerations, method of the development (a compatible or separate) of marine gas and gas hydrate of the fields (Fig. 8) is proposed. It provides:

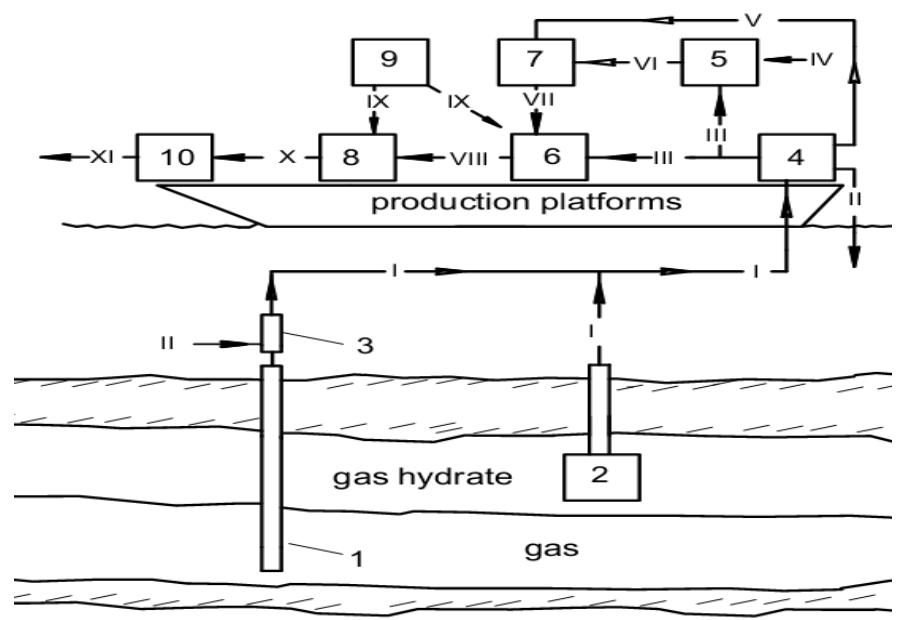

Fig. 8. Method of development (a compatible or separate) of the offshore fields of gas or gas hydrates: 1 - extraction of gas; 2 - extraction of gas hydrates; 3 - formation of a mixture of gas hydrates, gas and water; 4 - separation of the mixture of gas hydrates, water and gas on the gas, water (the gravitational) and the mixture that consists of gas hydrates, a film water and water captured between the crystals; 5 melting in the limited volume of party of the gas hydrates to obtain of gas flow of high pressure; 6 - draining of a mixture of gas hydrates, film and captured between crystals water by binding of remains of water in hydrates; 7 - compression in the jet compressor of gas flow, separated from the mixture due to the energy of flow gas of high pressure; 8 - a single cooling of gas hydrate mass; 9 - production of cold; 10 formation of gas hydrate blocks and their preservation with the ice layer; flows: I - a mixture of gas hydrates, water and gas; II - water; III - a mixture of gas hydrates, a film water and water captured between crystals; IV - supply of heat; $\mathbf{V}$ - gas of low pressure; VI - gas of high pressure; VII - gas of average pressure; VIII - gas hydrates; $\mathbf{I X}$ - the coolant

- uncovering of productive layers by the wells;

- impact on layer for the purpose of extraction of gas or gas hydrates;

- linking of the extracted gas in a gas hydrate;

- supply of gas hydrates mixture, water and gas to the extractive platform. This mixture at the developing of gas hydrate deposits is formed from extracted of gas hydrates, water, which carried destruc- 
tion of rocks, and the gas of released from hydrate as a result dissociation to create the effect of gas-lift in the pipeline. At the development of gas deposits mixture forms as a result of contact natural gas and sea water in process of removal of heat through the walls of the pipeline in the site with the thermo-baric conditions of the hydrate formation;

- separation of the mixture for gas, the gravitational water and mixture, which is composed of gas hydrate, a film water and water captured between the crystals;

- melting in the limited volume of the part the gas hydrate for receiving of gas of a high pressure for its further use in machineless compression (Makogon, 2001);

- compression of the separated from the mixture of gas of low pressure in the jet compressor due to the energy of the gas flow of a high pressure ;

- draining (concentration) of mixture gas hydrates and water (film and captured between the crystals) by binding it in the hydrate during it contact with the flow (refrigerated) of gas of the average pressure and removal of heat of the process;

- a single cooling obtained of the gas hydrate masses, taking into account of the heat balance the next of technological operations and processes up to the moment of gas consumption;

- formation of prepared gas hydrates in blocks and preservation with the ice layer;

- transportation and storage of gas hydrate blocks in terrestrial storages at atmospheric pressure and a temperature no higher than $278 \mathrm{~K}$.

\subsection{Storing gas in hydrate form}

The possibility of storage of natural gas in the form of gas hydrate, organization terrestrial storages of gas hydrates near large consumers of gas (Fig. 9) (Pedchenko, Pedchenko, 2013) is yet another promising direction use of gas hydrate technology. Building of similar storages could significantly smooth out the seasonal unevenness in gas production and represent an alternative to the construction of underground gas storage facilities. Moreover, these storages and technologies their exploitation can the best will supplement the tech- 
nological chain of production, transportation and storage of natural gas of the marine deposits.

To increase the effectiveness of the proposed technology hydrate blocks must be stored under a layer of polyurethane (thickness of 0.5-0.7 m) in terrestrial Inflatable structures covered with doublelayer soft shell with nonflammable gas locking layer. These structures present constructions that lies on the gas cushion with pressure above atmospheric only to maintain the shell (Fig. 9).

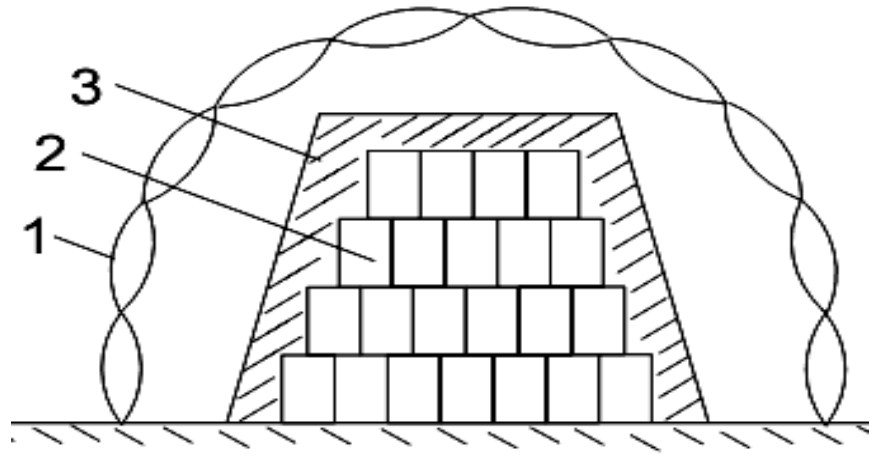

Fig. 9. Scheme storage of gas hydrates: 1 - elastic the double-layer shell; 2 - hydrate blocks; 3 - layer of polyurethane

To place such storage we propose near of gas consumers. This will allow give gas to distribution networks of low pressure. Therefore hydrate dissociates at a pressure of 0.3-0.4 MPa, and therefore at a much lower temperature (coolant temperature to melt the hydrate will not exceed $283 \mathrm{~K}$ ). Calculation of parameters of storage of the gas hydrates (2800 tons) in the terrestrial inflatable structures is given in the table 1 and Fig. 10 - the dynamics of temperature change on the surface of hydrate.

Cost of storage during the year in terrestrial Inflatable structures of the gas hydrate blocks amount to in terms of gas 15.86 thousand. $\mathrm{m}^{3}$, representing only $0.3 \%$ of the content terrestrial inflatable structures. In the production of of gas hydrates to $80 \%$ of the energy is consumed for recycling heat from the process. Before the gas consumption of the same amount of energy expended on melting hydrate. To improve efficiency of the technologies, dissociation of the gas hydrate blocks in the summer must be carried out by solar energy. 
Table 1

Calculation of parameters of storage of the gas hydrates in terrestrial inflatable structures

\begin{tabular}{|c|c|c|}
\hline The thermodynamic parameters & January & July \\
\hline \multicolumn{3}{|l|}{ Thermal resistance, $\left(\mathrm{m}^{2} \cdot \mathrm{K}\right) / \mathrm{W}$ : } \\
\hline - transition heat, $R_{\alpha}$ & 0.23 & 0.09 \\
\hline - coating of the layer of PVC, $R_{\mathrm{pvc}}$; & 0.025 & 0.025 \\
\hline - locking layer, Rloc; & 0.22 & 0.18 \\
\hline - covering (no layer of polyuret.), $R_{\text {cov }}$ & 0.34 & 0.28 \\
\hline - covering (with a layer of polyuret.), $R_{\mathrm{pu}}$ & 17.0 & 16.6 \\
\hline \multicolumn{3}{|l|}{ The heat flow to the hydrates, $\mathrm{W} / \mathrm{m}^{2}$ : } \\
\hline - without insulation polyurethane, $q$; & 20.58 & 104.1 \\
\hline - insulated with polyurethane, $q_{\mathrm{pu}}$ & 0.64 & 92.4 \\
\hline $\begin{array}{l}\text { The heat flux in the Inflatable structures to of gas } \\
\text { hydrates, } \mathrm{kW} \text { : }\end{array}$ & 80.77 & 409.0 \\
\hline $\begin{array}{l}\text { - without insulation polyurethane } Q_{\mathrm{ext}} \\
\text { - insulated with polyurethane, } Q_{\mathrm{ext}} \mathrm{pu}\end{array}$ & 2.53 & 9.36 \\
\hline The flow of heat from the earth, $Q_{\text {ear }} \mathrm{kW}$ & 9.0 & 9.0 \\
\hline Energy consumption for cooling, $Q_{\text {cool }} \mathrm{kW}$ & 6.6 & 15.3 \\
\hline
\end{tabular}

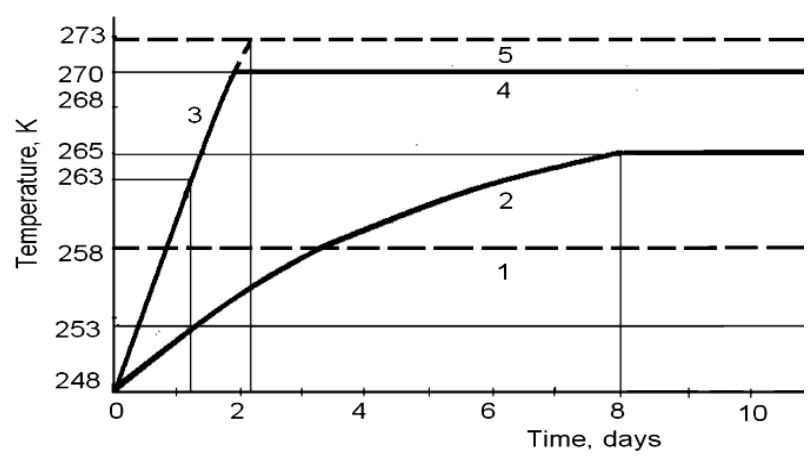

Fig. 10. Dynamics of change of surface temperature of gas hydrates in ground storage: limit of hydrate stability 1 - without preservation; 2 - winter without additional cooling; 3 - summer without additional cooling; 4 - summer with additional cooling; 5 - force preservation with the layer of ice

\subsection{Technological complex}

Accordingly, the proposed technological chain (Fig. 11), which involves: 


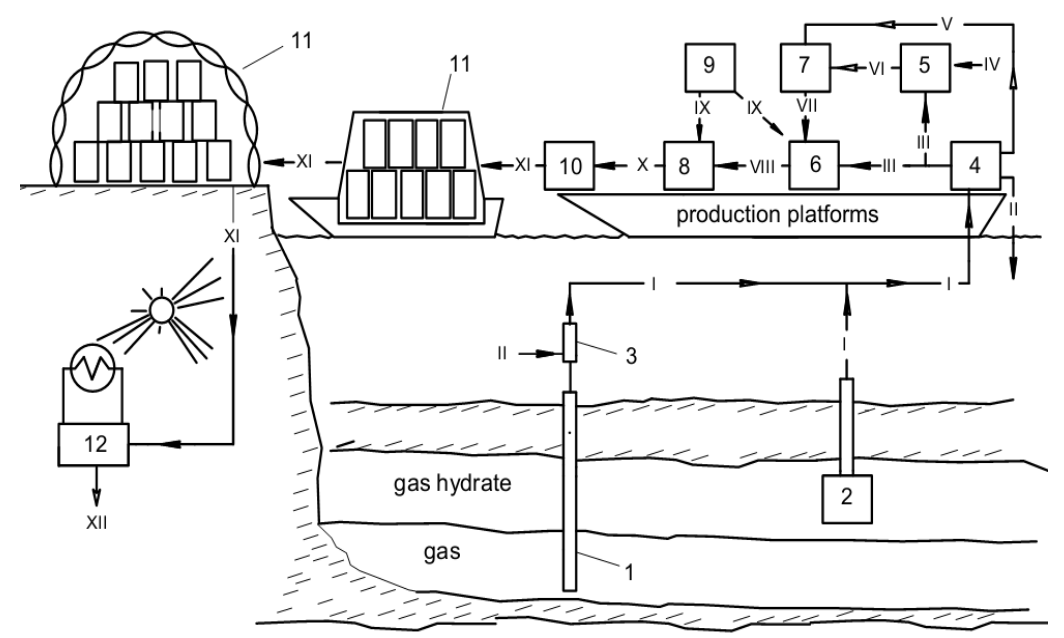

Fig. 11. Technological complex of production, transportation and storage of gas of the offshore fields of gas or gas hydrates: 1 - extraction of gas; 2 - extraction of gas hydrates; 3 - formation of a mixture of gas hydrates, gas and water;

4 - separation of the mixture of gas hydrates, water and gas on the gas, water (the gravitational) and the mixture that consists of gas hydrates, a film water and water captured between the crystals; 5 - melting in the limited volume of party of the gas hydrates to obtain of gas flow of high pressure; 6 - draining of a mixture of gas hydrates, film and captured between crystals water by binding of remains of water in hydrates; 7 - compression in the jet compressor of gas flow, separated from the mixture due to the energy of flow gas of high pressure; 8 - a single cooling of gas hydrate mass; 9 - production of cold; 10 - formation of gas hydrate blocks and

their preservation with the ice layer; 11 - transport and storage of gas hydrate blocks; 12 - dissociation of gas hydrates due to solar energy; flows: $\mathbf{I}$ - a mixture of gas hydrates, water and gas; II - water; III - a mixture of gas hydrates, a film water and water captured between crystals; IV - supply of heat; $\mathbf{V}$ - gas of low pressure;

VI - gas of high pressure; VII - gas of average pressure; VIII - gas hydrates;

IX - the coolant; $\mathbf{X}$ - cooled gas hydrate; $\mathbf{X I}$ - hydrate blocks, preservation with the ice layer; XII - gas on consumption

- extraction from deposits (hydrate and / or gas) products mainly in the form of moistened gas hydrates and partly - free gas, linking of this gas and the remaining water in the gas hydrates; 
- production of gas hydrates in the form of gas hydrate blocks of its transportation without additional cooling, storage vaults in the ground at a temperature of $270 \mathrm{~K}$, hydrate melting by solar energy.

\section{Conclusions}

1. The proposed method of extraction and transportation of natural gas from the offshore fields of gas or gas hydrate allows to receive technical result, which bears the maximum reduction of energy consumption as a result of a complex consideration of thermal properties and parameters of interaction of components of the system within the deposit, that the development.

2. The main idea of the proposed method of development of gas hydrate deposits is extracting the maximum amount from gas hydrates productive strata without spending of energy on the phase transition and dissociation its residue, given the physical properties, is carried out due of low energy of the sea water and changing its pressure with depth.

3. Proposed gas hydrate technology creates important preconditions of development of small and medium-sized remote of gas fields (including gas-hydrate), creating a network of terrestrial Inflatable structures, improve the efficiency and competitiveness of marine technologies of transporting of natural gas in hydrate form.

4. The use of alternative energy sources (natural cold and solar energy) at the production and dissociation of gas hydrate in terrestrial Inflatable structures allows considerably reduce capital and energy costs of the technological chain of the transportation and storage of hydrocarbon gases in hydrate form.

5. At their insignificant improvement of existing search technology, exploration, drilling and production of hydrocarbon energy resources can be successfully used for the development of gas hydrate deposits. Implementation of the gas hydrate technology allows abandon more of complex and expensive system of preparation, transportation and storage of the extracted products. 
6. Works on the borehole hydro- mining in the world do not have direct analogs by type of the extracted ores and by the parameters of the hydro-destruction. Furthermore, the parameters of the used hydraulic equipment in the borehole hydro-mining in connection with the specifics of this method of extraction also do not have analogues in the known hydraulic systems. Therefore testing of the proposed method development of gas hydrate deposits requires a number of experimental studies.

References

1. Arens. V.. Babichev. A.. Bashkatov. A.. Gridin. O.. Khrulev. A.. \& Khcheyan. G. (2007). Borehole Hydro-Mining: Proc. Manual. Mining Book, 2007. 295.

2. Basniev. K.. Kul'chitskiy. V.. Shchebetov. A.. \& Nifantov. A. (2006) Methods for the Development of Gas Hydrate Deposits. Gas industry. 7. 22-24.

3. Beznosikov. A.. \& Maslov. V. (1975). Influence of Water Ice Hydrates in the Reservoir on its Permeability. Proceedings VNIIEGazproma. 8. 84-89.

4. Dawe. R.. Thomas. M.. \& Kromah. M. (2003). Hydrate Technology for Transporting Natural Gas. Engineering Journal of the University of Qatar. 16. 11-18.

5. Gudmundsson. J. (1996). Method for Production of Gas Hydrates for Transportation and Storage. U.S. Patent US5536893 MPK C07C 7/20. 16 July 1996.

6. Gudmundsson. J.. \& Borrehaug. A. (1996). Natural Gas Hydrate an Alternative to Liquified Natural Gas. Trondheim, 1996, January. http://www.ipt.unit.no/ jsg/forskning/hydrater

7. Gudmundsson. J.. Graff. O.. \& Kvaerner. A. (2003). Hydrate non-pipeline Technology for Transport of Natural Gas. 22nd World Gas Conference Tokyo. http://members.igu.org/html/wgc2003/WGC_pdffiles/10056_1046347297_14776_1. pdf

8. Gudmundsson. J.. \& Parlaktuna. M. (1991). Gas-in-ice: Concept Evaluation. Technical report, Department of Petroleum Engineering and Applied Geophysics, Norwegian University of Science and Technology. Trondheim.

9. Gudmundsson. J.. M. Parlactuna. M.. \& Khokhar. A. (1994). Storing Natural Gas as Frozen Hydrate. SPE Production \& Facilities. 9 (1). 69-73.

10. Kanda. H. (2006). Economic Study on Natural Gas Transportation with Natural Gas Hydrate (NGH) Pellets. 23rd World Gas Conference, Amsterdam. http://members.igu.org/html/wgc2006/pdf/paper/add10399.pdf.

11. Kvenvolden. K. (1993). Gas Hydrates -Geological Perspectives and Global Change. Rev. Geophysics. 31. 173-187. 
http://eesc.ldeo.columbia.edu/courses/w4937/Readings/Kvenvolden.1993.pdf

12. Makogon. Yu. (2001). Natural hydrates: Opening and Prospects. Gas industry. 5. 10-16.

13. Pedchenko. L.. \& Pedchenko. M. (2014). Application of Liquid-gas Jet Apparatus with an Elongated a Camera of Mixing as a Contact Device for the Formation of Gas Hydrates. Ukraine Patent for Invention № 105208, 25 April 2014.

14. Pedchenko. L.. \& Pedchenko. M. (2012). Substantiation of Method of Formation of Ice Hydrate Blocks with the Purpose of Transporting and Storage of Hydrate Gas. Scientific Bulletin DGU. 127(1). 28-34.

15. Pedchenko. L.. \& Pedchenko. M. (2013). Calculation of Thermodynamic Parameters of Gas Hydrates Storage in Terrestrial Storage Facilities. Collections of the Scientific Labor SWorld. Iss. 4. Vol. 17. Ivanovo: Markov AD. 107-118. http://www.sworld.com.ua/konfer33/1257.pdf

16. Rehbinder. G. (1980). A Theory about Cutting Rock with Water Jet. Rock Mechanics. 12. 247-257.

17. Seungyong. C. (2001). Comparing Exploitation and Transportation Technologies for Monetisation of Offshore Stranded Gas. SPE Asia Pacific Oil and Gas Conference and Exhibition: Indonesia, Jakarta, 2001, 17-19 April.

http://www.onepetro.org/mslib/servlet/onepetropreview?id=00068680.

18. Shnyukov. E.. Gozhik. P.. Krayushkin. V.. \& Klochko. V.(2007). On the Eve of the World of Submarine Methane Hydrate Extraction. Reports of National Academy of Sciences of Ukraine. 6. 125-134.

19. Timothy. S. (2010). Geologic Implications of gas Hydrates in the Offshore of India: Results of the National Gas Hydrate. Program Expedition 01 - Marine \& Petroleum Geology, Volume 58, Part A, December 2014, 12. http://energy. usgs. gov -2010 .

20. Vasilev. A.. \& Dimitrov. L. (2002). Evaluation of the Spatial Distribution and the Reserves of Gas Hydratesin the Black Sea. Geology \& Geophysics. 43(7). 672-684. http://www.gashydat.org

21. Yakushev. V.. Gerasimov. Yu.. Kvon, V.. \& Istomin. V. (2008). The Current State of the Gas Hydrate Technology. Review. Inf. OOO "Gazprom RPI". 88. 